Original Research Paper

\title{
Pemanfaatan Perangkat Lunak Sistem Informasi Akreditasi Program Studi dengan 9-Standar dalam Penyusunan Dokumen Akreditasi Berdasarkan Instrumen Akreditasi Program Studi 4.0 (IAPS 4.0)
}

\author{
Giri Wahyu Wiriasto ${ }^{1}$, Misbahuddin ${ }^{2}$, Muhamad Syamsu Iqbal ${ }^{3}$, A.Sjamsjiar Rachman ${ }^{4}$, Djul \\ Fikry Budiman ${ }^{5}$, L. Syamsul Irfan Akbar ${ }^{6}$ \\ 1,2,3,4,5,6 Electrical Engineering Department, Faculty of Engineering - University of Mataram, Mataram, \\ Indonesia.
}

DOI: https://doi.org/10.29303/jpmpi.v3i2.523

Sitasi:. Wiriasto, G. W., Misbahuddin., Iqbal. M. S., Rachman, A. S., Budiman, D. J., \& Akbar, L. S. I. (2020). Pemanfaatan Perangkat Lunak Sistem Informasi Akreditasi Program Studi dengan 9-Standar dalam Penyusunan Dokumen Akreditasi Berdasarkan Instrumen Akreditasi Program Studi 4.0 (IAPS 4.0). Jurnal Pengabdian Magister Pendidikan IPA, 3(2)

\section{Article history}

Received: 25 Oktober Revised: 15 Nopember Accepted: 29 Nopember

*Corresponding Author: Giri Wahyu Wiriasto Electrical Engineering, University of Mataram Email: support@thescipub.com

\begin{abstract}
Currently, the preparation of accreditation forms is required to use the latest instruments that have been provided by the National Accreditation Board which is also known as the Study Program Accreditation Instrument 4.0 (IAPS4.0). This instrument uses 9-standards or criteria and is very different from the previous accreditation instruments which still used 7-standards. Filling in this instrument really requires supporting data from each performance indicator that is carried out and reported in relation to the implementation of activities within the organization of the Study Program Management Unit and Study Program. To assist in the preparation of the accreditation process we have prepared a software system in the form of online-based software, so that the supporting data, both LKPS data and LED data, can be uploaded whenever and wherever the IAPS 4.0 drafting team works. . There is also a simulation software system available to measure the achievement of program performance indicators. Another benefit achieved is how to prepare the Accreditation process in a measured and effective manner. This software system has been developed and tested in the Electrical Engineering Study Program, Mataram University. As a result, during the trial, the accreditation drafting team consisting of lecturers could and still work in a participatory manner in inputting accreditation documents. Until now this software system has been developed to reach $100 \%$ and has been installed or implemented to support IAPS4.0 and can also simulate the evaluation of the performance achievements of the current study program. This system or software already has an economic value that will generate revenue generating for the laboratory business unit.
\end{abstract}

Keywords: IAPS 4.0 ; Sistem Akreditasi 9-standar ;

\section{Pendahuluan}

Dalam Peraturan Menteri Pendidikan dan Kebudayaan No.5 Tahun 2020 disebutkan Akreditasi Program Studi (APS) merupakan kegiatan penilaian untuk menentukan kelayakan Program Studi. Secara umum, Akreditasi juga merupakan Sistem Penjaminan Mutu Eksternal sebagai bagian dari Sistem Penjaminan Mutu Pendidikan Tinggi, dimana : a). menentukan 
kelayakan Program Studi dan Perguruan Tinggi berdasarkan kriteria yang mengacu pada Standar Nasional Pendidikan Tinggi (SN-Dikti); dan b). menjamin mutu Program Studi dan Perguruan Tinggi secara eksternal baik bidang akademik maupun non akademik untuk melindungi kepentingan mahasiswa dan masyarakat. Program Studi adalah kesatuan kegiatan pendidikan dan pembelajaran yang memiliki kurikulum dan metode pembelajaran tertentu dalam satu jenis pendidikan akademik, pendidikan profesi, dan/atau pendidikan vokasi. Akreditasi dilakukan terhadap Program Studi dan Perguruan Tinggi berdasarkan Standar Nasional Pendidikan Tinggi dengan perolehan peringkat Unggul, Baik Sekali atau Baik. Dalam implementasinya, Proses Akreditasi Program Studi dilakukan dengan menggunakan instrumen Akreditasi. Dalam Peraturan BAN-PT No.2 dan 5 Tahun 2019, disebutkan Instrumen Akreditasi Program Studi (IAPS) terdiri dari Laporan Evaluasi Diri (LED) dan Laporan Kinerja Program Strudi (LKPS) dan disebut APS 4.0. Panduan dalam Peraturan ini dirinci menjadi beberapa bagian lampiran (Lampiran Peraturan BAN-PT No.5 Tahun 2019). Diantaranya terdapat : a). Naskah Akademik IAPS 4.0 ; b). Kriteria dan Prosedur IAPS 4.0 ; c). Panduan Penyusunan Laporan Evaluasi Diri (LED) IAPS 4.0; d). Panduan Penyusunan Laporan Kinerja Program Studi (LKPS) IAPS 4.0, e). Pedoman Penilaian IAPS 4.0, f). Matriks Penilaian IAPS 4.0, g). Pedoman Asesmen Lapangan IAPS 4.0.

Mengingat arti pentingnya mekanisme akreditasi bagi institusi perguruan tinggi, dan banyaknya indikator yang akan diukur serta perlu disiapkan data dukungnya maka kami dari tim pengabdian Masyarakat mengusulkan kegiatan ini.

\section{Metode}

Dalam tahapan pelaksaan pengabdian ini, aktifitas kegiatan terbagi menjadi dua tahapan, yakni pertama aktifitas pengembangan system perangkat lunaknya, kedua aktifitas ujicoba dan pengisian data boring instrument akreditasi dengan 9-standar. Pada tahapan kedua, pendekatan yang kami gunakan untuk proses ujicoba dan pengisian data borang menggunakan metode Partisipatif. Metode Partisipatif Ini artinya setiap anggota bertanggung jawab untuk menyelesaikan beberapa isian data yang mana tim dapat bekerja secara Bersama-sama dalam waktu dan ruang yang tidak dibatasi, mengingat system perangkat lunak ini berbasis online sehingga dapat diakses kapan dan dimanapun. Secara teknis Anggota tim telah terbagi mengikuti jumlah isian indikator pada IAPS 4.0, diantaranya yaitu Indikator Kriteria Visi,misi, Tujuan dan Strategi ; Indikator kriteria tata pamong, tata kelola dan kerjasama ; kriteria mahasiswa ; kriteria sumber daya manusia (SDM) ; kriteria keuangan, sarana dan prasarana ; kriteria pendidikan ; kriteria penelitian ; kriteria pengabdian kepada masyarakat ; kriteria luaran dan capaian tridharma.

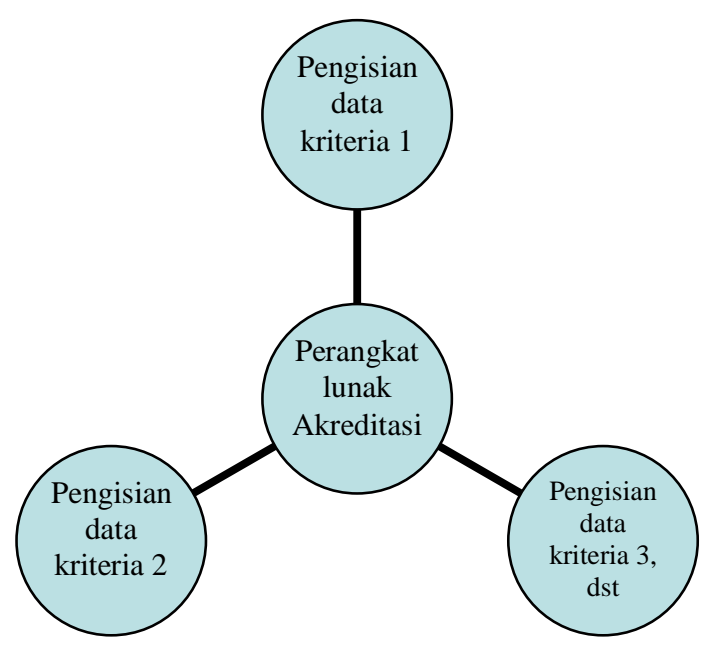

Gambar 1 . Ilustrasi Tim kerja pengisian IAPS 4.0
berbasis perangkat lunak

\section{Hasil dan Pembahasan}

I. Matriks indikator penilaian sebagai luaran system Perangkat lunak

Mengacu pada instrument matriks perhitungan capaian indikator kinerja, berikut ini kami tampilkan ilustrasi perhitungan bobot indikator.

Tabel 1. Simulasi dan Bobot perhitungan capaian indikator kinerja

\begin{tabular}{|l|l|l|l|}
\hline No & \multicolumn{1}{|c|}{ Elemen } & $\begin{array}{c}\text { Bobot } \\
/ 100\end{array}$ & $\begin{array}{c}\text { Total } \\
\left(\begin{array}{c}\text { Bobot } x \\
\text { Skor)* }\end{array}\right.\end{array}$ \\
\hline 1 & A. Kondisi External & 0.010 & 0.0300 \\
\hline 2 & B. Profil Unit Pengelola & 0.010 & 0.0300 \\
\hline
\end{tabular}




\begin{tabular}{|c|c|c|c|}
\hline No & Elemen & $\begin{array}{l}\text { Bobot } \\
/ 100\end{array}$ & $\begin{array}{l}\text { Total } \\
\text { ( Bobot x } \\
\text { Skor)* }\end{array}$ \\
\hline & Program Studi & & \\
\hline 3 & $\begin{array}{l}\text { C. Kriteria C.1. Visi, Misi, } \\
\text { Tujuan dan Strategi } \\
\text { C.1.4. Indikator Kinerja Utama }\end{array}$ & 0.005 & 0.0200 \\
\hline 4 & & 0.010 & 0.0300 \\
\hline 5 & & 0.015 & 0.0450 \\
\hline 6 & $\begin{array}{l}\text { C.2. Tata Pamong, Tata Kelola } \\
\text { dan Kerjasama } \\
\text { C.2.4. Indikator Kinerja Utama } \\
\text { C.2.4.a) Sistem Tata Pamong } \\
\end{array}$ & 0.003 & 0.0090 \\
\hline 7 & $\begin{array}{l}\text { C.2.4.b) Kepemimpinan dan } \\
\text { Kemampuan Manajerial }\end{array}$ & 0.003 & 0.0120 \\
\hline 8 & C.2.4.c) Kerjasama & 0.007 & 0.0210 \\
\hline 9 & & 0.003 & 0.0090 \\
\hline 10 & $\begin{array}{l}\text { C.2.5 Indikator Kinerja } \\
\text { Tambahan }\end{array}$ & 0.007 & 0.0210 \\
\hline 11 & C.2.6 Evaluasi Capaian Kinerja & 0.010 & 0.0300 \\
\hline 12 & C.2.7. Penjaminan Mutu & 0.014 & 0.0420 \\
\hline 13 & $\begin{array}{l}\text { C.2.8. Kepuasan Pemangku } \\
\text { Kepentingan }\end{array}$ & 0.014 & 0.0420 \\
\hline 14 & $\begin{array}{l}\text { C.3. Mahasiswa } \\
\text { C.3.4. Indikator Kinerja Utama } \\
\text { C.3.4.a) Kualitas Input } \\
\text { Mahasiswa }\end{array}$ & 0.046 & 0.1840 \\
\hline 15 & $\begin{array}{l}\text { C.3.4.b) Daya Tarik Program } \\
\text { Studi }\end{array}$ & 0.031 & 0.0930 \\
\hline 16 & \begin{tabular}{|l|} 
C.3.4.c) Layanan \\
Kemahasiswaan \\
\end{tabular} & 0.015 & 0.0600 \\
\hline 17 & $\begin{array}{l}\text { C.4. Sumber Daya Manusia } \\
\text { C.4.4. Indikator Kinerja Utama } \\
\text { C.4.4.a) Profil Dosen }\end{array}$ & 0.007 & 0.0280 \\
\hline 18 & & 0.010 & 0.0300 \\
\hline 19 & & 0.005 & 0.0200 \\
\hline 20 & & 0.005 & 0.0143 \\
\hline 21 & & 0.010 & 0.0400 \\
\hline 22 & & 0.003 & 0.0120 \\
\hline 23 & & 0.005 & 0.0161 \\
\hline 24 & C.4.4.b) Kinerja Dosen & 0.008 & 0.0231 \\
\hline 25 & & 0.008 & 0.0038 \\
\hline 26 & & 0.004 & 0.0022 \\
\hline 27 & & 0.008 & 0.0320 \\
\hline 28 & & 0.008 & 0.0320 \\
\hline 29 & & 0.008 & 0.0320 \\
\hline 30 & C.4.4.c) Pengembangan Dosen & 0.022 & 0.0660 \\
\hline 31 & C.4.4.d) Tenaga Kependidikan & 0.011 & 0.0330 \\
\hline 32 & $\begin{array}{l}\text { C.5. Keuangan, Sarana dan } \\
\text { Prasarana } \\
\text { C.5.4. Indikator Kinerja Utama } \\
\text { C.5.4.a) Keuangan }\end{array}$ & 0.008 & 0.0080 \\
\hline
\end{tabular}

\begin{tabular}{|c|c|c|c|}
\hline No & Elemen & $\begin{array}{l}\text { Bobot } \\
/ 100\end{array}$ & $\begin{array}{l}\text { Total } \\
\text { ( Bobot x } \\
\text { Skor)* }\end{array}$ \\
\hline 33 & & 0.008 & 0.0320 \\
\hline 34 & & 0.004 & 0.0160 \\
\hline 35 & & 0.004 & 0.0120 \\
\hline 36 & & 0.008 & 0.0240 \\
\hline 37 & C.5.4.b) Sarana dan Prasarana & 0.031 & 0.0930 \\
\hline & $\begin{array}{l}\text { C.6. Pendidikan } \\
\text { C.6.4. Indikator Kinerja Utama } \\
\text { C.6.4.a) Kurikulum }\end{array}$ & 0.025 & 0.0750 \\
\hline 39 & $\begin{array}{l}\text { C.6.4.b) Karakteristik Proses } \\
\text { Pembelajaran }\end{array}$ & 0.010 & 0.0300 \\
\hline 40 & $\begin{array}{l}\text { C.6.4.c) Rencana Proses } \\
\text { Pembelajaran }\end{array}$ & 0.017 & 0.0510 \\
\hline & $\begin{array}{l}\text { C.6.4.d) Pelaksanaan Proses } \\
\text { Pembelajaran }\end{array}$ & 0.011 & 0.0330 \\
\hline 42 & & 0.006 & 0.0217 \\
\hline 43 & $\begin{array}{l}\text { C.6.4.e) Monitoring dan } \\
\text { Evaluasi Proses Pembelajaran }\end{array}$ & 0.025 & 0.0750 \\
\hline 44 & $\begin{array}{l}\text { C.6.4.f) Penilaian } \\
\text { Pembelajaran }\end{array}$ & 0.017 & 0.0510 \\
\hline 45 & $\begin{array}{l}\text { C.6.4.g) Integrasi kegiatan } \\
\text { penelitian dan PkM dalam } \\
\text { pembelajaran }\end{array}$ & 0.017 & 0.0680 \\
\hline 46 & C.6.4.h) Suasana Akademik & 0.025 & 0.0750 \\
\hline 47 & C.6.4.i) Kepuasan Mahasiswa & 0.034 & 0.1020 \\
\hline 48 & $\begin{array}{l}\text { C.7. Penelitian } \\
\text { C.7.4. Indikator Kinerja Utama } \\
\text { C.7.4.a) Relevansi Penelitian }\end{array}$ & 0.015 & 0.0450 \\
\hline 49 & $\begin{array}{l}\text { C.7.4.b) Penelitian Dosen dan } \\
\text { Mahasiswa }\end{array}$ & 0.031 & 0.0632 \\
\hline 50 & $\begin{array}{l}\text { C.8. Pengabdian kepada } \\
\text { Masyarakat } \\
\text { C.8.4. Indikator Kinerja Utama } \\
\text { C.8.4.a) Relevansi PkM } \\
\end{array}$ & 0.005 & 0.0150 \\
\hline 51 & $\begin{array}{l}\text { C.8.4.b) PkM Dosen dan } \\
\text { Mahasiswa }\end{array}$ & 0.010 & 0.0205 \\
\hline 52 & $\begin{array}{l}\text { C.9. Luaran dan Capaian } \\
\text { Tridharma } \\
\text { C.9.4. Indikator Kinerja Utama } \\
\text { C.9.4.a) Luaran Dharma } \\
\text { Pendidikan } \\
\end{array}$ & 0.019 & 0.0570 \\
\hline 53 & & 0.019 & 0.0693 \\
\hline 54 & & 0.029 & 0.0870 \\
\hline 55 & & 0.010 & 0.0000 \\
\hline 56 & & 0.019 & 0.0000 \\
\hline 57 & & 0.019 & 0.0000 \\
\hline 58 & & 0.019 & 0.0000 \\
\hline 59 & & 0.029 & 0.0870 \\
\hline 60 & & 0.029 & 0.1160 \\
\hline \begin{tabular}{|l|}
61 \\
\end{tabular} & & 0.019 & 0.0215 \\
\hline
\end{tabular}




\begin{tabular}{|l|l|c|c|}
\hline No & \multicolumn{1}{|c|}{ Elemen } & $\begin{array}{c}\text { Bobot } \\
/ 100\end{array}$ & $\begin{array}{c}\text { Total } \\
\text { Bobot x } \\
\text { Skor)* }\end{array}$ \\
\hline 62 & & 0.019 & 0.0760 \\
\hline 63 & & 0.038 & 0.0517 \\
\hline 64 & $\begin{array}{l}\text { C.9.4.b) Luaran Dharma } \\
\text { Penelitian dan PkM }\end{array}$ & 0.029 & 0.0006 \\
\hline 65 & & 0.010 & 0.0400 \\
\hline 66 & $\begin{array}{l}\text { D Analisis dan Penetapan } \\
\text { Program Pengembangan } \\
\text { D.1 Analisis dan Capaian } \\
\text { Kinerja }\end{array}$ & 0.015 & 0.0450 \\
\hline 67 & $\begin{array}{l}\text { D.2 Analisis SWOT atau } \\
\text { Analisis Lain yang Relevan }\end{array}$ & 0.020 & 0.0600 \\
\hline 68 & $\begin{array}{l}\text { D.3 Program Pengembangan } \\
\text { 69 }\end{array}$ & 0.015 & 0.0450 \\
\hline D.4 Program Keberlanjutan & 0.010 & 0.0300 \\
\hline data skor merupakan nilai simulasi dari \\
pendekatan studi kasus
\end{tabular}

Dari tabel 1, dapat kita amati terdapat 69 indikator yang akan diukur data kualitatifnya dan kuantitatifnya. Dari tabel 1 tersebut terdapat sebaran skor bobot yang lebih besar pada indikator tertentu semisal indikator luaran dan capaian tridharma.

II. Gambaran Sistem perangkat lunak dari tangkapan layar.

Secara keseluruhan, system perangkat lunak kami ilustrasikan pada gambar 2, gambar 3, gambar 4 dan gambar 5. Masing-masing gambar mewakili tampilan sesungguhnya system perangkat lunak yang telah dikembangkan.

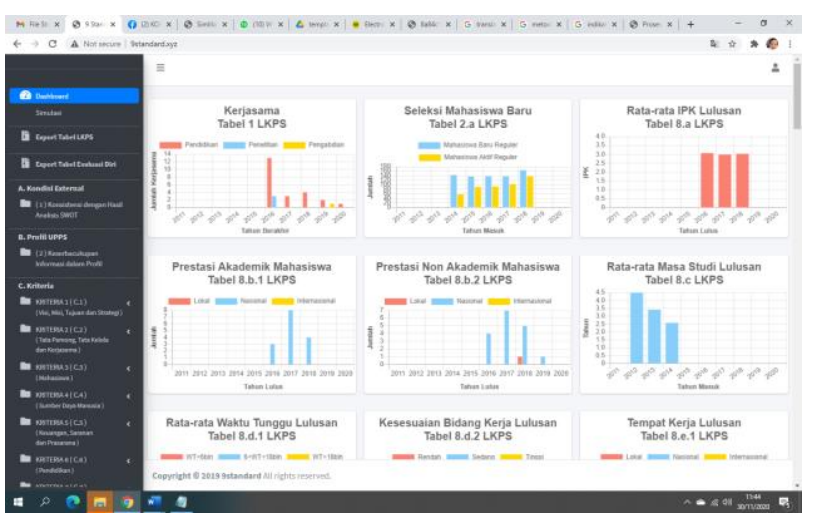

Gambar 2 : Tampilan halaman utama system perangkat lunak, menunjukkan data yang telah diinput dalam bentuk grafik dari setiap indikator kinerja

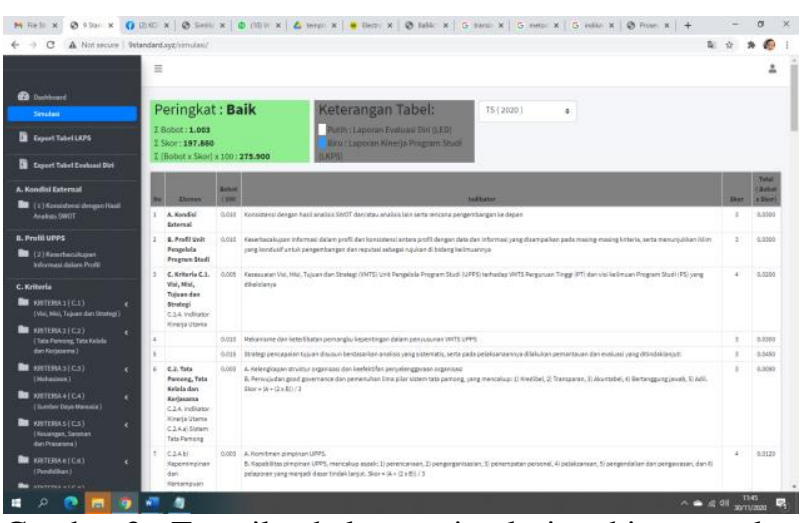

Gambar 3 : Tampilan halaman simulasi perhitungan skor dan bobot dari indikator kinerja
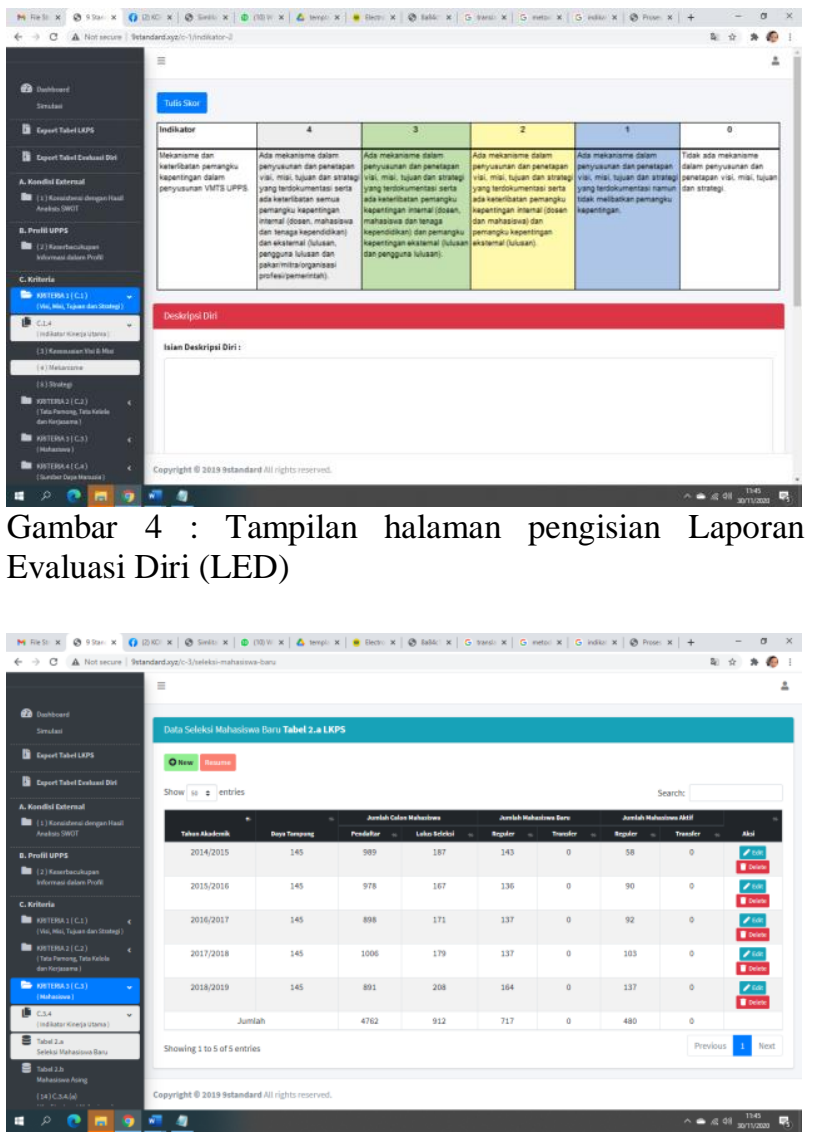

Gambar 5 : Tampilan halaman data Laporan Kinerja Program Studi (LKPS)

\section{Kesimpulan}

Dari kegiatan yang telah kami laksanakan, dapat kami simpulkan beberapa capaian antara lain : pertama, pengisian data Laporan Kinerja Program Studi (LKPS) tidak mengalami kendala dan berhasil dihimpun.; kedua, pengisian dokumen Laporan Evaluasi Diri (LED) memerlukan data 
dukung yang lengkap dari tingkat UPPS (unit pengelola program Studi), diperlukan koordinasi yang terintegrasi agar memudahkan dalam penyusunan dokumen LED; ketiga, Sistem perangkat lunak telah berhasil dikembangkan dan telah terinstall pada laman https://9standard.xyz ; keempat, system perangkat lunak telah memiliki alat ukur simulasi untuk mengukur indikator kinerja.

\section{Saran}

Sistem ini dapat dikembangkan lebih lanjut dan dapat diintegrasikan pada Sistem Satuan Penjamin Mutu Internal (SPMI).

\section{Ucapan Terima Kasih}

Penulis mengucapkan terima kasih kepada Universitas Mataram yang telah mendanai kegiatan Pengabdian Kepada Masyarakat tahun 2020.

\section{Daftar Pustaka}

Agustiansyah Riza, Kiswanto, Kusumasari F. Tien, "Perancangan Aplikasi Pengelolaan Dokumen dan Simulasi Penilaian Akreditasi di Prodi S-1 Sistem Informasi Universitas Telkom", Jurnal Rekayasa Sistem \& Industri Volume 4 Nomor 1 Juni 2017.

Astirin Parama Okid, "Hilirisasi Produk Riset Melalui Kegiatan Pengabdian Kepada Masyarakat". SniemaS UAD ISBN 978-6020737-07-2, 2018

Flask https://flask.palletsprojects.com/en/1.1.x/serv er/.

Lampiran-lampiran Peraturan BAN-PT tahun 2019 mengenai Instrumen penyusunan LED (Laporan Evaluasi Diri), Penyusunan LKPS ( Laporan Kinerja Program Studi), Matriks Penilaian Indikator LED, Instrumen Assesment.

Laudon C. Kennet and Laudon P. Jane, Management Information System, Thirteenth Edition, Pearson 2014.

Peraturan BAN-PT Nomor 1 tahun 2020 tentak Juknis APS 4.0

Peraturan BAN-PT Nomor 2 Tahun 2019 tentang Akreditasi Prodi menggunakan IAPS 4.0 Standar 9-Kriteria

Peraturan Mendikbud Nomor 5 tahun 2020 tentang Akreditasi Prodi-PT
T. Basaruddin, "Akreditasi di Kampus Merdeka". slide presentasi Direktur BAN-PT tahun 2020. 